\title{
SOBRE ALGUNOS ASPECTOS DEL QUEHACER LEXICOGRÁFICO
}

\author{
MANUEL FERNANDO PÉREZ LAGOS \\ (Universidad de Málaga)
}

\begin{abstract}
RESUMEN
Considering that the major part of lexicography is learnt "on the worktable as problems arise", this work highlights these specific aspects concerning the making of a dictionary (the number of entries, the way they are presented, etymology, grammar and register labels, definition and its problems, examples) which arise from and during the lexicographical practice itself, and not from reflection on the great works on lexicographical theory produced in recent years.
\end{abstract}

Quizás el no familiarizado con la práctica lexicográfica espera encontrar bajo títulos como el de este trabajo aquellas fórmulas y mecanismos de redacción que permitan dar a un diccionario la consistencia global que necesita dentro de la extremada fragmentación de sus informaciones. Y es que cada día toma mayor auge lo que se ha venido a llamar lexicografía teórica, y los trabajos que la están constituyendo se han convertido en pilares básicos para la formación inicial del lexicógrafo. Sin embargo, no podemos obviar que estas teorizaciones carecen de validez si no son surgidas a raíz de una práctica lexicográfica. Queremos recordar, por ello, las palabras de Julio Casares en los preliminares de su Introducción a la lexicografía moderna, cuando afirma que la lexicografía es

una disciplina que no se enseña en ninguna Universidad ni se explica en ningún tratado; y puesto que [...] tiene más de técnica que de ciencia, lo que necesita el que quiera llegar a dominarla no son tanto teorías como advertencias, consejos y menudas habilidades de taller, fruto de la experiencia, y que conviene aprender en la mesa de trabajo a medida que las dificultades se presentan!.

Julio CASARES, Introducción a la lexicografía moderna, Madrid, 1950, p. XIV. 
Sin ánimo de teorizar, por tanto, intentaremos mostrar algún que otro aspecto muy concreto de las posibles fragmentaciones de un diccionario, acompañando su descripción de las reflexiones y observaciones que nos han surgido en nuestros años de redacción de diccionarios.

\section{Sobre el número de entradas de un diccionario}

A la hora de comprar un diccionario el futuro usuario suele atender a dos puntos fundamentales: el prestigio de la marca editorial y el mayor o menor número de palabras que ofrece.

Parece muy importante para el comprador del diccionario que éste le ofrezca una gran cantidad de palabras, y si es posible alguna más que otros diccionarios que ha visto del mismo tipo. Es por ello que las editoriales se esfuerzan en destacar en las cubiertas el número de entradas reunido, y en ocasiones exagerando en gran medida.

La editorial, mirando por sus intereses comerciales, debe procurar contentar al futuro comprador ofreciéndole gran cantidad de información, pero no puede perder por ello la calidad y seriedad que un entendido exigiría en el tipo de diccionario de que se trate, ya que son estos expertos los que conceden el prestigio a la editorial y a sus diccionarios.

Sin embargo, se puede conseguir que el número de entradas de un diccionario sea mayor o menor sin afectar a su tamaño y, además, justificar teóricamente que no por ello se ha salido de las características y calidades exigidas al tipo de diccionario en cuestión.

Entre los factores que intervienen de forma conjunta en la determinación del número de entradas destacaremos los siguientes:

- el grado o nivel de competencia léxica, tanto activa como pasiva, que se quiera suponer en el usuario al que va dirigido el diccionario;

- la elección, como más apropiada para el diccionario en cuestión, de una macroestructura pobre o de una macroestructura rica;

- la elección, como más apropiada para el diccionario en cuestión, de una microestructura pobre o de una microestructura rica.

De todas maneras, es preciso no olvidar que este número de entradas es una cifra muy relativa. No es lo mismo, y casi ningún diccionario lo especifica, el número de entradas que el número de palabras distintas: pensemos, por ejemplo, en la colocación o no de las variantes gráficas en un solo artículo o entrada, así como en la variable interpretación de la homonimia y polisemia por parte del lexicógrafo a la hora de decidir la existencia o no de dos homógrafos. 


\section{Sobre la inclusión en la macroestructura de palabras en mayúscula y de las procedentes de nombres propios}

Pensamos que en un diccionario de lengua debe evitarse la aparición de palabras que sólo tienen acepciones con uso en mayúscula, propias de una obra puramente enciclopédica, ya que su presencia sólo serviría para hacer notar otras muchas ausencias.

Los nombres de dioses y héroes mitológicos, libros o personajes bíblicos, nombres de estrellas o constelaciones que pueden encontrarse en algunos de estos diccionarios no tienen razón de ser ${ }^{2}$.

En aquellos casos en los que el frecuente uso en mayúscula haría precisa su inclusión bajo esta forma, debe establecerse un sistema de notas aclaratorias sobre la obligación ortográfica de escribirla en mayúscula en ese sentido específico que definimos. Así, por ejemplo, en entradas como piscis o Piscis creemos conveniente:

piscis (l.) $\boldsymbol{n}$. p. $\boldsymbol{m}$. Duodécimo signo del Zodíaco... 2 Constelación... -3 adj.-com. [pers.] Nacido entre el 19 de febrero y el 20 de marzo... \# En las dos primeras acepciones se escribe con mayúscula.

Esta indicación gramatical-ortográfica debe aparecer también en otros artículos de diccionario con entrada en minúscula, pero que tienen acepciones de habitual uso en mayúscula, sobre las que, hasta ahora, no se había indicado nada (nos referimos, por ejemplo, a algunas acepciones de tierra, sol o papa).

Las siglas, abreviaciones y símbolos sólo deben ser contemplados en la macroestructura cuando posean una realidad fónica propia y si funcionan como parte del discurso.

No tiene sentido, así pues, entradas o artículos de diccionario en mayúscula indicadores simplemente de un símbolo químico o de una abreviatura (por ejemplo, Fe, Sr.).

Por otra parte, a diferencia de la actitud académica y pese a las posibles repercusiones jurídicas, es preciso incluir en las nomenclaturas aquellos nombres procedentes de marcas comerciales, al menos cuando envían a todo objeto del mismo tipo y actúan como nombres comunes ordinarios. Si se descartan de la nomenclatura nombres como martini, chupachups, uralita, etc., se está empobreciendo la descripción del léxico.

En cuanto a las voces derivadas de nombres de personas, también deben ser considerados en las nomenclaturas de los diccionarios, especialmente todos aquellos que han adquirido contenidos precisos a partir de imágenes socioculturales y particulares del referente y no son una simple interpretación de los elementos morfosemánticos del nombre que les sirve de base. Si todo nombre propio de persona

2 Vid., por ejemplo, el Diccionario General Ilustrado de La Lengua Española de la editorial VOX, donde podemos encontrar voces como Hera, Heracles, Herodías, Proción o Mizar. 
puede tomar notoriedad y actualidad en el discurso de nuestra lengua y admitir derivaciones léxicas ordinarias, será la extensión de su uso y el grado de asentamiento en nuestro léxico quien determine en última instancia su inclusión o no en la macroestructura?.

\section{Sobre la forma de presentación de los lemas o entradas}

El lema, como representante de todas las variantes de la palabra, viene tradicionalmente constituido por el infinitivo para los verbos, el singular para los sustantivos y el masculino singular para los adjetivos y pronombres.

Sin embargo, en no pocos casos de entradas gramaticales será necesario romper esta unidad de criterio. Así, por ejemplo, si se quieren ofrecer todos los elementos que constituyen el sistema gramatical del artículo, de los demostrativos, de los personales o de los posesivos, es necesario para ello, al corresponderles diferentes posiciones de orden alfabético, considerar cada forma como una entrada independiente ${ }^{4}$. Aún así, el diccionario debe hacer referencia a todas las variantes desde la forma masculina singular representante.

No por evidente hay que dejar de recordar que la entrada es el primer referente y guía que tiene el usuario del diccionario para encontrar la información que busca, y, por ello, en el tratamiento de este apartado del artículo lexicográfico debe imperar la búsqueda de la mayor claridad de los contenidos, dejando para otras zonas del artículo todas cuantas informaciones aquí se tenga la tentación de aportar.

\section{Sobre los valores semánticos aportados por el género}

Un punto delicado para su determinación con el que se enfrenta el lexicógrafo es el establecimiento de cuándo el género no es más que una variante morfológica y cuándo es pertinente a nivel semántico. Mientras que en el adjetivo suele ser un dato de lengua (es masculino o femenino según el sustantivo con el cual es empleado en cl discurso), en el nombre no depende de ninguna otra palabra del discurso y generalmente están desprovistos de contenido semántico.

Sin embargo, en un gran número de palabras con doble terminación (masculina y lemenina), la marca morfológica del género femenino corresponde a una diferencia sémica.

La mayoría de los diccionarios actuales muestran gran incoherencia interna en cuanto a la posible separación de este tipo de entradas. Cada uno presenta una forma

3 Sobre la presencia de los nombres propios y sus derivados en los diccionarios, cfr. Josette ReyDebove, Étude linguistique et sémiotique des dictionnaires français contemporains, La Haya-París, 1971, pp. 88-90.

4 Sobre el tema de la repartición de los elementos de los microsistemas gramaticales, cfr. Josette Rey-Debove, op. cil., p. 148. 
distinta de enfrentarse con el tema y todos cllos se ven obligates a incumplir alguna! que otra ver, y según criterios subjetivos, el sistema que han establecido.

Si separan sólo algunos masculinos y femeninos, habria que precisall muy bien cuáles, no sólo para evitar subjetividades e incoherencias, sino también calibrar el incremento de entradas que el cambio puede suponer. Piénsesce ademais. que un diccionario habitual pretende presentar una lista de lemas y no de paliahris flexionadas.

En este sentido, la misma justificación tiene presentar una entrada para conejo y otra para coneja, que presentar una para celo y otra para celos. ¿Qué criterio ha de suponer el usuario que se hal seguido para presentar en entradas independientes tío y tía. mientras que sobrino y sobrina se ofrecen en la misma entradal? ¿Por qué lechera tiene como acepeión 'Mujer que vende leche', y en lechero, -ra soilo se queda la acepción masculina. mientras que conejera no lleva la acepejón de 'Mujer que cría y vende concjos', sino que se incluye en la acepeion de m.f. de conejero,-ra"? Parece de escasa rentabilidad. para la aportación informativa que supone. sacrilican espacios ofreciendo, por cjemplo, una entrada para elefanta. siendo la siguiente entrada clefante.

Otros diecionarios, basides estrietamente en yue la emtada es sóle una forma paradigmática indicadora de las matreas alfabéticals a partir de las cuales buscall. y no de contenidos. agrupan bajo una misma entrada lodos aquellos signilicados que puedan ser representados por alguno de los significantes prosibles a partir del paradigma indicado.

Esta opción, si bien simplitical el múmero de entradas y coonomiza espacio. presupone un buen conocimiento gramatical y léxico por parte del usuario. Asi. pror ejemplo, debe saber que para encontrar cara ('rostro') debe ir a caro, -ra. Por otra parte, se suele producir cierta ambigüedald en la colocación de lats locuciones: frases hechas, al igual que diliculta su búsqueda.

Nuestra experiencia demuestra gue es más importante la coherencia mantenida que el sistema elegido. Lo principal es facilitar al ustario la comsulta de lo que desea y. entre otras cosals, debe explicársele en la presentación del diccionatrio el criterio adoplado.

La pestura intermedia que cabe adoptar sólo habilita una entrada lemenina independiente para acpuelles casos en que dicho significante poseat akeperiones exclusivamente suyals.

Se mantiene así en una sola entrada de diccionario aguellas palabras sustantivas en las que la forma femenina sólo constituye una indicación de género y lambién acquellas en las que se aprovecha la marca mor femáticat para hacer una indicacion de sexo. Nos referimos a los nombres de animales. de prolesiones o de parenteseo. lin ellos el contenido de las dos formals sólo difiere en la oposición macho/hembra masculino/lemenino5.

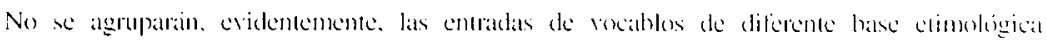

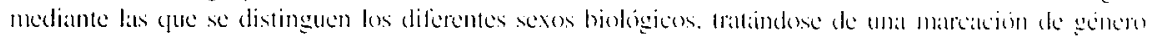


Se ofrecerán, pues, las definiciones que hacen referencia conjunta ( $\boldsymbol{m} . \boldsymbol{f} .$, adj., adj.-s.) a los dos significantes. A continuación, si las hubiese, se presentarían las acepciones referentes exclusivamente al masculino (también al masculino plural), ya que, al coincidir con la forma desarrollada en el paradigma, hasta el usuario más inexperto buscaría en el artículo de diccionario en que nos hallamos. Son las acepciones exclusivamente referidas al femenino las que deben ser ofrecidas en una entrada independiente que presente la forma femenina (blanca, lechera, perforadora, mora, niña, cerda, etc.).

Para mantener el criterio seguido no se debe poner la acepción femenina del animal o del profesional en aquellas entradas en las que, por otras acepciones exclusivas del femenino, haya sido preciso crear una entrada independiente (nos referimos al caso de gata - gato, -ta o al de lechera - lechero, -ra). No se debe confundir lo que decimos con aquellas acepciones femeninas que hacen referencia, en determinadas profesiones, a la mujer del profesional (por ejemplo, capitana, sargenta).

\section{Sobre la presencia de información etimológica}

En ocasiones se ha escrito sobre la no pertinencia de la información etimológica en los diccionarios descriptivos modernos, ya que ésta en ellos habrá de ser extremadamente sumaria cuando no incompleta, pues una presentación completa y detallada de este tipo de información es propia de diccionarios diacrónicos o históricos y, en propiedad, de un diccionario etimológico ${ }^{6}$.

Antes de decidir sobre la presencia o no de etimología es necesario considerar los dos tipos de informaciones básicas que puede aportar: dar cuenta de su origen y creación, por un lado, y analizar su formación estableciendo relaciones entre palabras afines, por otro.

Se distingue, así, entre etimología propiamente dicha (mediante étimos que no pertenecen al mismo estado de lengua) y análisis de formación (donde se analiza un derivado indicando la base en sincronía).

En cualquiera de los casos se debe ofrecer información etimológica sólo cuando ésta enriquezca o suponga un incremento de la información aportada por el conjunto del artículo.

En unos casos será preciso indicar la lengua de origen, el étimo y su significado, pero también será frecuente que esté ausente la significación del étimo al ser la misma que la ofrecida en el artículo e incluso el étimo por mantener el vocablo la misma forma que en su lengua origen.

puramente semántica: caballo/yegua, padre/madre.

Véase también los planteamientos de Julio Casares sobre Etimología y Lexicografía en el capítulo I de su Introducción a la lexicografia, ya citado, pp. 29-49. 
En los vocablos compuestos la información etimológica puede limitarse a la identificación de los elementos que intervienen o a la simple indicación de que es un derivado o un parasintético junto al vocablo del que surge.

La información en voces extranjeras, asentadas en nuestro léxico pero no adaptadas a nuestra estructura fonológica o gráfica, debe limitarse a la indicación de la lengua original en cuestión.

Serán casos especiales otras etimologías que informan sobre la lexicalización de nombres propios o de siglas (por ejemplo, zepelín o láser) o la procedencia de nombres comerciales (por ejemplo, aspirina).

La tradicional ubicación de estas informaciones entre la entrada y el resto de las informaciones, se explica por la proximidad que guarda de este modo con la primera acepción, la cual es la que con más exactitud sigue el sentido del étimo (ya que el artículo del diccionario ha venido ofreciendo sus significados ordenados según la antigüedad de su afincamiento en nuestra lengua); otra justificación de esta tradicional ubicación es su cercanía con el representante paradigmático sobre el que informa.

De cualquier manera, sí es conveniente que esta información sea presentada con un aspecto que la distinga claramente de los diferentes bloques de contenido que ofrece un artículo léxico, de forma que goce de tal independencia que pueda ser evitada su lectura por parte del usuario sin dificultad, e incluso que pueda ser optativa su plasmación o no en la edición impresa por parte de la editorial.

\section{Sobre algunas marcaciones gramaticales de las acepciones}

No se debe concebir la indicación gramatical, que habitualmente se ofrece antes de cada definición, como indicadora de la categoría o parte de la oración a la que pertenece la palabra representada en el artículo de diccionario, sino que pertenece y funciona dentro del bloque de la acepción como informadora de la función gramatical que desempeña ese significante representado en la entrada cuando lo empleamos en el sentido que se define.

Si bien existe la posibilidad de informar de que una acepción determinada suele ser usada también en otra función gramatical, bien mediante la unión por un guión de esta segunda etiqueta a la ya indicada, bien mediante su exposición al final de la acepción, convendría no abusar de ello, pues la complicación y amalgama de marcaciones gramaticales puede causar dudas y ambigüedades en el usuario. Siempre será preferible simplificar la información en este lugar de etiquetación y aportar otros posibles usos en una glosa complementaria sobre la acepción.

Un ejemplo concreto sobre la necesidad de extremar la claridad en este apartado de información gramatical lo encontramos en la frecuentemente descuidada etiquetación de «también usado como pronominal» (tr.-prnl., intr.-prnl.), pues no es lo mismo, por ejemplo, enfadar ('causar enfado') que enfadarse ('sentir enfado'), y no se puede presentar, por tanto, con una sola acepción con marca de tr.-prnl., sino 
dar en una acepción propia el uso pronominal siempre que éste adquiera nuevas connotaciones semánticas.

\section{Sobre la marcación de niveles de la definición que sigue}

En este apartado inmediatamente anterior a la definición se emplean una serie de marcas que informan de las condiciones de empleo del significante con el contenido que a continuación se ofrece.

Si dejamos a un lado la marcación gramatical, la geográfica y la técnica o temática, podemos ocuparnos de un grupo de etiquetas que podemos dividir en tres apartados fundamentales: las referencias a vigencia de uso (ant., desus., p. us....), las referencias a niveles lingǘsticos o sociolingüísticos (vulg., pop., fam....) y las referencias a transiciones de sentido (fig., p. ext....).

Aunque estas acotaciones de uso son difíciles de marcar siguiendo criterios rigurosos, e incluso de delimitar unas respectr ' a otras, ya que intervienen criterios intuitivos del lexicógrafo, pror un lado, y var: tes contextuales y situacionales, por otro, es preciso mantener sisıematicidad y curierencia.

La marcación sobre la vigencia de la palabra aparece cuando se pretende inlormar sobre su bajo empleo. La dificultad está en establecer el grado o medida de desuso, cómo aquilatar si se trata de un empleo arcaico o anticuado, desusado o sólo poco usado (ant., desus., p. us.). Conviene recordar que esta etiquetación no está referida a aquellos vocablos referidos a cosas o conceptos que han caído en desuso, sino a las palabras que los nombran (la palabra puede estar vigente aún en la competencia del hablante y tratarse de una realidad no existente en la actualidad).

En un diccionario que pretenda ser descriptivo del español actual, este tipo de acepciones deben tender a desaparecer. La presencia de algunas de ellas sólo está justificada como muestra o información de la tendencia al desuso de un definido hasta hace poco normalmente usado. Pero, por otra parte, todas las acepciones de este tipo deben ser conocidas y estar presentes en el fondo lexicográfico de la editorial, pues bien pueden más adelante volver a ser de uso extendido.

También es difícultosa la marcación rigurosa de la restricción a un determinado nivel lingiístico. Es cierto que lo que para unos es «vulgar» para otros es simplemente «popular» o «familiar», y en la inarcación de nivel selecto ocurre lo mismo, no siempre es fácil distinguir entre «interario» y «poético», al menos si no se especifica en algún sitio que por literario se entiende todo vocabulario elevado o selecto empleado generalmente en codificación escrita y no oral. Aunque puedan ser discutibles estas etiquetas son valiosas, al menos, para indicar que la acepción no forma parte del español que podríamos llamar estándar y que no está libre de connotaciones que la sitúan por encima o por debajo de este nivel.

Las marcaciones con información significativa o de sentido (despectivo, ligurado, irónico, humorístico, festivo, eufemístico) muestran una transición semántica desde definidos anteriores (mostrando la interrelación entre distintas 
acepciones dentro de la unidad superior que es el artículo de diccionario) y son útiles para el usuario, pues sin ellas la definición puede inducir a falsas interpretaciones y el usuario no se explica la relación entre el contenido expuesto y el significante empleado.

No sicmpre será fácil distinguir entre «irónico» y «burlesco», o entre «humorístico»y «festivo», pero lo esencial es dejar constancia de la connotación existente y scrá el lexicógrafo el que elija la más apropiada en cada ocasión.

\section{Sobre la definición}

Claridad, precisión y concisión son las tres normas básicas a la hora de la elaboración de cualquier definición. El equilibrio entre estas tres premisas debe proporcionar una definición fácilmente inteligible y que ofrezca todas las informaciones que pueda necesitar el usuario.

Sería deseable que todas las palabras que se empleen en 'a definición no sólo estén contenidas en el diccionario a su vez como entradas, sino que formaran parte de una lista de delinidores. La elección de dichos definidores estará supeditada en cuanto a su número a las características del diccionario.

En la selección de los definidores, previa evidentemente a la elaboración del diccionario, es imprescindible contar con una estructura jerarquizada de contemplación ideológica de la realidad o el universo, la cual permitirá la etiquetación semántica de cada definición y la elección del definidor apropiado que la represente. Y es que el conocimiento de la valoración conceptual a la que pertenece el contenido que se pretende definir, facilitará enormemente la elección del tipo de definición y la selección de los definidores que se deben utilizar. Todo ello redundará en la tan deseada sistematicidad y coherencia interna del diccionario.

La definición de estos definidores debe ofrecer con todo rigor y exactitud todas las posibilidades de empleo significativo del vocablo y, además, sin necesidad de recurrir para su completo entendimiento a ninguna otra entrada del diccionario.

En estricta lexicografía teórica y científica la definición lexicográfica habría de rellejar directamente (de manera formalizada) el análisis componencial por semas que corresponde al contenido referencial de determinado significante. Pero, independientemente de las teorías lingüísticas, el objeto de la definición lexicográfica es dar al usuario una información que le permita usar e interpretar correctamente signos léxicos en su papel de emisor o receptor. En una producción lexicográlica que se realice en plan comercial para usuarios no precisamente interesados por la ciencia lingüística, es preciso, pues, mantener los tipos tradicionales de definición, si bien habrá de procurarse que los significantes léxicos utilizados actúen como sustitutos de los semas que corresponderían al contenido definido ${ }^{7}$.

Cabe recordar las palabras de José Álvaro Porto Dapena: «se hace imprescindible y neccsario -y hoy más que nunca- llegar a un sistema de definiciones lexicográficas objetiva y 
El principio general y fundamental para que una definición sea correcta es que ésta debe abarcar todo lo definido pero nada más que lo definido.

Si esta condición se cumple la definición correcta superará la prueba de la sustituibilidad: si el enunciado definidor puede sustituir al término definido, en un enunciado de habla, sin que el sentido objetivo de éste se altere, el enunciado definidor es válido.

Como consecuencia inmediata de esta ley de conmutabilidad debe darse una identidad categorial entre definido y definiente: el enunciado definidor poseerá una forma adecuada a la función sintáctica propia del definido.

La aplicación de los anteriores principios no es universal para todos los artículos del diccionario. Palabras gramaticales, interjecciones, etc., necesitan una definición que informe de ellas en cuanto signos del sistema, no en cuanto a su contenido. Cabe distinguir, pues, entre definiciones en metalengua de contenido o conceptuales (se considera el definido como unidad que hace referencia a la realidad y se pretende traducir en otras palabras de la misma lengua su contenido significativo) y definiciones en metalengua de signo o funcionales (se considera el definido sólo en tanto que elemento o signo del sistema de la lengua, por lo que se informa de sus valores y funciones dentro de la misma).

La definición ideal es la de tipo conceptual y debe utilizarse siempre que sea posible. Es preciso evitar definiciones innecesariamente de tipo híbrido, con mezcla de información conceptual y funcional.

No quiere decir esto que todas las informaciones funcionales deban ser excluidas de la definición, sólo que, en caso de considerarse pertinentes deben quedar claramente distinguidas de la parte conceptual ${ }^{8}$.

Dentro de la definición conceptual se vienen distinguiendo dos tipos fundamentales: la definición perifrástica y la definición sinonímica.

Aunque la definición sinonímica es frecuentemente tachada de inexacta e insuficiente (no existen verdaderos sinónimos y, por otra parte, no se produce análisis o descomposición del contenido de lo definido), en la práctica lexicográfica resulta inevitable utilizarla y no es incorrecta si se cumplen las siguientes condiciones:

- emplearla sólo en aquellas unidades léxicas que les corresponda idéntico o casi idéntico contenido referencial;

- que la definición sinonímica aparezca en la unidad que posee algún tipo de restricción (geográfica, de uso, etc.) y el término definidor ofrezca una definición perifrástica;

científicamente controlable, y para ello sería muy apropiado un metalenguaje formalizado, cosa que está todavía por inventar, aunque a decir verdad este procedimiento haría del diccionario una obra para especialistas, no para el público en general, que siempre preferirá las definiciones en su lengua natural», en Elemenlos de lexicografía, Bogotá, 1980, p. 299.

8 Véase más adelante lo que decimos sobre el contorno lexicográfico. 
- que no quede duda de a qué termino definidor se hace referencia (cuando el término usado como definidor sea polisémico habrá que indicar entre paréntesis a qué acepción se refiere, y, si existen otros homógrafos, habrá que indicar cuál de ellos cs el que empleamos);

- que no se ofrezca una simple relación de sinónimos, pues en ellas aparecen ambigüedades y vaguedades, ya que obligan a que el usuario, basado en su competencia, busque el sentido conjunto a partir de la selección de parte de, y no todos, los rasgos significativos de cada uno de ellos.

Con respecto a la definición conceptual perifrástica puede manifestarse bajo formas diversas teniendo en cuenta la naturaleza de la unidad por definir. Josette Rey-Debove" resume en el siguiente esquema los diferentes tipos:

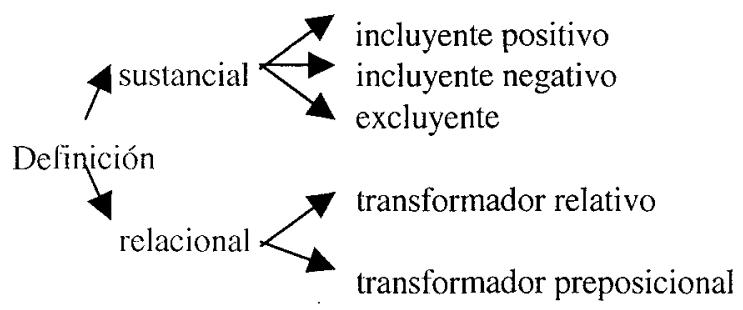

La definición sustancial es la que intenta responder a la pregunta «¿qué es el definido?». La respuesta puede presentarse desde su estructura lógica bajo tres formas:

- el definido es «tal cosa» (incluyente positiva);

- el definido es «no tal cosa» (incluyente negativa);

- el definido «es contrario» 0 «carece de tal cosa» (excluyente).

La definición incluyente positiva viene a ser el prototipo de definición lógica aristotélica que analiza el definido mediante el género próximo (palabra clasificadora cuya carga semántica abarca al definido) y la diferencia específica (encargada de concretar el significado del definido).

La caracterización del contenido de un definido ha de empezar, pues, por encontrar, dentro de la misma categoría lingüística, un elemento globalizador que permita una primera localización en el mundo de los conceptos más generales.

Evidentemente la elección del incluyente lógico clasificador vendrá guiada por los esquemas jerárquicos de etiquetación semántica y la lista de definidores que mencionábamos más arriba. Así, por ejemplo:

$$
\begin{aligned}
& \text { líquido } \longrightarrow \text { Cuerpo + en que se equilibran las fuerzas... } \\
& \text { bebida } \longrightarrow \text { Líquido + que se bebe } \\
& \text { sangría } \longrightarrow \text { Bebida + refrescante a base de vino... }
\end{aligned}
$$

9 Ch. Étude linguistique et sémiotique des dictionnaires français contemporains, ya citado, en su capítulo 6, pp. 180-257. 
Lá definición incluyente negativa sólo se distingue de la anterior en que se ofrece el incluyente lógico en sentido negativo. Al estar basada en las parejas de oposiciones que se suponen intuitivamente reconocidas por el usuario, debe usarse sólo con parejas sólidamente establecidas para que no se produzcan errores o ambigüedades (desasosegar - Privar de sosiego).

La definición excluyente, basada también en la existencia de parejas de contrarios, no analiza el contenido sino que sólo niega el opuesto del definido, dando por supuesto su análisis (ilegítimo - No legítimo).

Dentro de la definición sustancial, Álvaro Porto Dapena ${ }^{10}$ distingue dos tipos más de definición: la definición participativa y la definición aditiva.

En la definición participativa aparece un «falso incluyente», por lo que el género próximo no es independiente y este supuesto incluyente forma un todo con el resto de la predicación. El núcleo del sintagma está formado por una palabra con sentido partitivo o distributivo (especie de, parte de, cada uno de) seguida de un complemento que indica el todo.

Este tipo de definiciones, habituales en las obras lexicográficas, deben ser evitadas en la medida de lo posible, pues suponen el reconocimiento de no encontrar una unidad semántica superior. Así, por ejemplo, si definimos cimitarra como «Especie de sable...», indicamos que contiene rasgos significativos del 'sable', pero no es un sable. Es mejor, pues, definirla como «Arma blanca semejante a un sable...».

La defininición aditiva se caracteriza por la coordinación copulativa de varios elementos que expresan el contenido del definido. Cuando se trata de adición de lexemas sólo se diferencia de la definición sinonímica múltiple en el tipo de coordinación que establecen: copulativa para las aditivas y disyuntiva para las sinonímicas.

El otro tipo fundamental de definición, la definición relacional no remite a la sustancia del contenido, sino a la relación entre el definido cualificante y otra palabra cualificada. Contiene dos componentes: un elemento transformador, que puede ser un relativo (definición relativa) o una preposición (definición preposicional), el cual confiere a la palabra u oración que sirve de definidor (clemento traspuesto) el carácter de adjetivo o adverbio.

Dejando a un lado estos modelos formales de definición cabe destacar la llamada definición morfo-semántica, la cual se apoya en la forma compleja del definido pretendiendo que se establezca una identidad de contenidos a partir de la identidad parcial de formas. Utilizada en la definición de compuestos y derivados, la definición viene a resultar una descomposición de los elementos componentes, explicando cuando más la funcionalidad significativa de alguno de ellos (generalmente sufijos) en el complejo.

Op. cit., pp. 317-319. 
Relacionadas con este grupo estarían todas aquellas definiciones que empleando formas estereotipadas se despreocupan de la información conceptual y prestan información funcional de derivados nominales a partir de verbos (acción y efecto) o de adjetivos (calidad de), o de derivados adjetivos a partir de sustantivos (perteneciente o relativo).

Es evidente que para el usuario medio la lectura de estas definiciones no les aclara su contenido. Habría que procurar que estas definiciones sólo aparezcan con la finalidad de informar del carácter y procedencia de su formación, y se acompañaran de otras definiciones específicas de su contenido.

Un último grupo característico de definiciones es aquél que en su perífrasis definicional emplea elementos que sólo son interpretables a partir de otra definición que ya ha sido expuesta (marta - Piel de este animal; coca - Hoja de este arbusto; plato -. Vianda o manjar que se sirve en los platos).

Estos usos especiales, que no son incorrectos si concebimos la definición no como una predicación aislada sino como un elemento más interrelacionado con el resto en la estructura del artículo", deben aparecer sólo como casos excepcionales, ya que su empleo dificulta la contemplación independiente de las unidades de contenido y el manejo de éstas en cualquier trabajo que precise la selección de sentidos.

Los distintos tipos y formas de definición que hemos caracterizado no pueden utilizarse indistintamente, sino que la naturaleza categorial o semántica del definido exigirá como más apropiado algún tipo en particular.

El modo más común de definir el sustantivo es el conceptual perifrástico de tipo sustancial en cualquiera de sus modalidades. No obstante existen algunas unidades sustantivas que inevitablemente son definidas de forma funcional, al estar desgastadas semánticamente y reducir su empleo a determinados esquemas o clisés (señorita $\longrightarrow$ Tratamiento de cortesía que...)

En cl caso de los adjetivos, junto a la definición funcional aplicable en el caso de los adjetivos gramaticales (suyo, suya -Forma de la $3^{a}$ persona...), es frecuente la definición sustancial, en la que el adjetivo se define mediante otro adjetivo (incluyente lógico) acompañado de una complementación que actúa como diferencia específica, y también la definición relacional, siendo más frecuentes las de modalidad relativa (herbiforme - Que tiene forma de hierba).

En cuanto a los verbos, aunque existen algunos definidos funcionalmente, especialmente los copulativos y auxiliares, son definidos generalmente en su modalidad conceptual, tanto sinonímica como perifrástica.

También son frecuentes las definiciones verbales de tipo aditivo, en las que el verbo es definido por la suma de significados de los verbos coordinados en la definición.

11 Véase para este aspecto concreto el trabajo de Manuel Alvar Ezquerra, «El diccionario, texto cerrado», que aparece ahora en su Lexicografía descriptiva, Barcelona, 1993, pp. 73-78. 
La definición más frecuente, sin embargo, es la sustancial incluyente positiva: el verbo se define mediante otro verbo de significado más general (incluyente lógico) seguido de uno o varios complementos (diferencia específica).

Cuando el verbo definido es transitivo el verbo definidor elegido como incluyente ha de ser también transitivo. En fórmula de Manuel Seco ${ }^{12}$ : V. tr. $^{1}=$ $\left\langle\mathrm{V} . \operatorname{tr}^{2}{ }^{2} »\right.$. Este verbo transitivo definidor puede aparecer solo en definición sinonímica (enrolar tr. Alistar.), o con complementaciones en definición perifrástica, especialmente complementos adverbiales (substraer tr. Hurtar, robar fraudulentamente).

Un grupo muy extendido de definiciones es el realizado mediante un verbo transitivo de amplio contenido (hacer, causar, producir, etc.) + un sustantivo surgido desde el definido, que como objeto directo 'interno' recorta la extensión del transitivo definidor (indizar $t r$. Hacer índices).

En las definiciones de verbo intransitivo puede emplearse tanto un verbo transitivo como intransitivo. En fórmula de Manuel Seco: V. intr. ${ }^{1}=\left\langle V\right.$. intr. ${ }^{2} »$; V. intr. ${ }^{\prime}=\langle\mathrm{V}$. tr. + c.d.». Pueden ser sinonímicas (galopear intr. Galopar) o perifrásticas, en las que las estructuras más frecuentes son las de v. tr. + objeto directo (silbar intr. Dar o producir silbos o silbidos) y la de v. intr. + c. adverbial (reptar intr. Andar arrastrándose como los reptiles), aunque en ocasiones aparece la de v. prnl. + adj. predicativo (palidecer intr. Ponerse pálido).

En las definiciones de los pronominales pueden aparecer las estructuras anteriores, tanto de los transitivos como de los intransitivos (descuadrillarse prnl. Derrengarse [las bestias] por el cuadril).

Las definiciones de los unipersonales pueden ser realizadas con la presencia de otro verbo unipersonal, tanto en sinonimia como en perífrasis (diluviar unipers. Llover copiosamente), o en construcciones bimembres con indicación expresa del sujeto (anochecer unipers. Empezar a faltar la luz del día).

\section{Sobre tres temas ya clásicos de la práctica definicional}

a) La definición lexicográfica «no se orienta a la realidad, sino a aprehender la visión que la comunidad ha configurado de la realidad a través de la lengua» ${ }^{13}$. Aquellas definiciones que pretenden ofrecer el máximo número de especificadores, una imagen completa del objeto definido, son propias de un diccionario de cosas y no de un diccionario de palabras.

No obstante, en aquellos términos, especialmente de botánica y zoología, es necesario olvidarse de los puntos de vista puramente teóricos y procurar que la definición permita al usuario establecer una relación suficiente entre el significante léxico y la experiencia de la realidad que le corresponde. Sólo en estas ocasiones,

12 Cfr. sus trabajos «Problemas formales de la definición» y «El "contorno" en la definición» recogidos en su Estudios de lexicografía española, Madrid, 1987, pp. 15-34 y 35-45, respectivamente.

13. Julio Fernández Sevilla, Problemas de lexicografia actual, Bogotá, 1974, p. 77. 
cuando la simple exposición de los rasgos semasiológicos no resultaría clara y comprensible, se utilizarán estas definiciones descriptivas o enciclopédicas que hagan también referencia a la experiencia de la realidad.

b) $\mathrm{Si}$ el diccionario pretende analizar las unidades léxicas de un sistema lingüístico, cada unidad léxica ha de ser definida por medio de otras unidades léxicas que también serán objeto de la misma descripción. El círculo vicioso se hace inevitable si el redactor no se esfuerza por explicar el contenido de cada unidad léxica mediante unidades léxicas de mayor carga semántica. Son estas definiciones circulares las que provocan más detractores de algunos diccionarios y las que desaniman en gran medida a los que se inician en su uso.

Aún así el problema se planteará en el momento de definir las palabras situadas en los niveles superiores. ¿Cómo definir ser, objeto, cosa, haber, etc. sin recurrir a la tautología o emplear unidades de niveles inferiores? Sólo cabe en estas unidades últimas, abandonar el análisis y recurrir a una suma de casos de aplicación refiriendo las explicaciones no al concepto sino a la palabra que lo expresa, esperando que así se suministre una idea intuitiva del significado de la palabra.

c) Para que la prueba de la sustitución entre la entrada y su definición sea posible es preciso delimitar claramente lo que en ésta constituye enunciado conceptual de lo que pertenece a otras informaciones adicionales.

En el caso de los adjetivos debe limitarse en el contorno, cuando sea necesario, el tipo de sustantivo o sustantivos a los cuales se limita el uso de la voz. Quedará limitada entre corchetes esta información sobre el signo como tal y totalmente independiente de la definición conceptual propiamente dicha.

En el caso de los verbos debe limitarse, por ejemplo entre corchetes, toda aquella información que, no perteneciendo al nivel del contenido, supone los condicionamientos restrictivos del definido en cuanto al sujeto, complemento directo o preposicional regido. Conviene recordar que el hecho de estar indicando el objeto directo potencial del definido no significa que en la unidad sintáctica delinidora deba cumplir esta función (embridar - Poner la brida [a las caballerías]).

También en los intransitivos es posible marcar un contorno lexicográfico en función sujeto (marchar intr. Andar o moverse [un artefacto]... Caminar [la tropa] con cierto orden).

En los sustantivos es posible marcar estas restricciones contextuales que no forman parte de la definición conceptual, si bien es escasamente aplicable entre otras cosas por la gran cantidad de definiciones descriptivas que se salen de lo establecido en la definición lógica (paramento - Adorno o atavío con que se cubre [una cosa]; rifa - Juego que consiste en sortear [una cosa] entre varios; pinchazo - Hecho o dicho con que se mortifica [a uno]...) 


\section{Sobre los ejemplos}

La importancia de los ejemplos en un diccionario queda magistralmente expuesta en las siguientes palabras de Julio Fernández Sevilla:

los ejemplos constituyen el contrapunto exacto de la definición, a la cual ilustran y, en cierta manera, completan. Tienen, por una parte, carácter de testigos y, por otra, constituyen la mejor prueba de la validez y la adecuación de la delinición. Frente al carácter clasificador de la definición, los ejemplos son netamente identificadores. Si la definición constituye un modelo general y abstracto, los ejemplos se comportan como modelos concretos que sirven al usuario del diccionario para repetirlos o para formar enunciados paralelos, con el aval del buen uso y con la garantía ${ }^{14}$.

Frecuentemente se ha insistido en la habitual escasez de ejemplos acompañando a las definiciones en los diccionarios españoles. De todas formas es preciso guardar una justa proporción, pues la necesidad de que sean numerosos no debe hacerlos innecesarios o redundantes.

En líneas generales los ejemplos han de ser actuales y pueden servir para complementar la significación aportada por la definición, mostrar el ámbito más frecuente de uso del vocablo o indicar su habitual contexto gramatical. Implícitamente informa sobre la sintaxis y morfología de la voz en cuestión (mediante el empleo de variantes del lema: en plural, formas verbales personales, construcciones habituales, etc.) y también sobre el entorno semántico o contextual en el que es habitual su uso. En definitiva la cualidad fundamental que deben poseer es la de ser realmente demostrativos del funcionamiento normal del significante definido en la lengua.

Pero el lexicógrafo no debería tomarse la libertad de inventar ejemplos como productos artificiales de laboratorio, sino que, para conseguir darles las cualidades anteriores, debe seleccionarlos adecuadamente a partir de las referencias aportadas por un completo corpus de textos, tanto escritos como orales.

Cabe recordar, por último, las dos condiciones básicas que debe cumplir todo ejemplo señaladas por Josette Rey-Debove ${ }^{15}$ : ser un enunciado que contenga la palabra-entrada y que ésta aparezca como mencionada dentro de un texto en uso.

Según el tipo de información que ofrecen sobre la entrada en cuyo artículo aparecen se pueden distinguir diferentes formas de ejemplificar:

a) ejemplos que informan sobre la cosa nominada por la entrada.

El enunciado debe conferir un valor general a la entrada. Los dos tipos más importantes de predicación que distingue son los del ejemplo enciclopédico y el ejemplo delinicional.

\footnotetext{
It Problemas de lexicografía actual, p. 78 .

15 Josette Rey-Debove, op. cit, pp. 258-311.
} 
Con el ejemplo enciclopédico el lexicógrafo consigue ofrecer datos sobre la cosa ausentes o sin lugar en el programa de microestructura (apuntador, en el Diccionario Intermedio de S.M.: «En los antiguos teatros, el apuntador se ocultaba del público en la concha del escenario»).

Con los ejemplos definicionales se testimonia ante todo la incertidumbre del lexicógrafo ante la definición que ha ofrecido (por temor a una definición demasiado larga o por no saber delimitar lo puramente definicional).

b) ejemplos que informan sobre el signo nominado en la entrada.

Además de los ejemplos explícitamente metalingüísticos (n... «Nieve empieza por $n \gg)$, recordemos que todo ejemplo informa implícitamente sobre el signo nominado cuando se presenta la entrada en plural o en algún tiempo verbal irregular.

Pero el mayor problema que presenta el ejemplo es lograr una máxima capacidad para significar el contenido de la palabra y servir con ello de prueba parcial a la definición. Como la palabra entrada puede aparecer en una infinidad teórica de frases, el lexicógrafo ha de seleccionar aquellos contextos con capacidad de restituir, al menos parcialmente, el contenido de la palabra. Evidentemente, en esta decodificación mental que se realiza, la intervención del nivel pragmático es decisiva. Así, por ejemplo, es preciso considerar aquel número de frases que presentan un mismo entorno inmediato ${ }^{16}$. De esta manera, se puede ofrecer en un cjcmplo un modelo de frase gracias al cual se pueda generar cantidad de frases particulares. Así, por ejemplo, «Oponer resistencia a alguien» representa lo mismo «el criminal opuso resistencia a la policía» que «opondrá fuerte resistencia a su adversario». Otra posibilidad de ejemplificar es la de la «acumulación»: así, cuando los elementos de un mismo paradigma realizados en numerosas frases no pueden ser tomados por un término general que los incluya, se presentan todos o varios de manera no limitativa y sobre un mismo eje sintagmático: «hacer la barba, la comida, la cama».

Como ya dijimos al inicio, no hemos pretendido hacer teorizaciones sobre lexicografía práctica, sólo hemos querido hacer hincapié sobre algunos aspectos que, si bien han sido tratados en los principales estudios sobre lexicografía existentes, también conviene verlos desde la experiencia y en su aplicación al quehacer lexicográlico diario.

16. Si, como cjemplifica Josette Rey-Debove (op. cit,, pp. 303-304), resistencia aparece frecuentemente acompañada de feroz, con exponer como ejemplo simplemente el sintagma «feroz resistencial» estaremos dando una amplia realización de la unidad de lengua en el discurso. 